OPEN ACCESS

Edited by:

Sam Salek,

University of Hertfordshire, United Kingdom

Reviewed by:

Debabrata Roy,

Drug Safety Research Unit, United Kingdom Deborah Layton,

IQVIA (United Kingdom), United Kingdom

*Correspondence:

Xiaosheng Wang xiaosheng.wang@cpu.edu.cn

Specialty section: This article was submitted to Pharmaceutical Medicine and

Outcomes Research,

a section of the journal

Frontiers in Pharmacology

Received: 24 September 2020 Accepted: 06 January 2021

Published: 15 March 2021

Citation:

Abdelrahman Z, Liu Q, Jiang S, Li M, Sun Q, Zhang Y and Wang X (2021) Evaluation of the Current Therapeutic Approaches for COVID-19: A Systematic Review and a Metaanalysis.

Front. Pharmacol. 12:607408. doi: 10.3389/fphar.2021.607408

\section{Evaluation of the Current Therapeutic Approaches for COVID-19: A Systematic Review and a Meta-analysis}

\author{
Zeinab Abdelrahman ${ }^{1,2}$, Qian Liu ${ }^{1,2}$, Shanmei Jiang ${ }^{1,2}$, Mengyuan $L^{1,2}{ }^{1,}$, Qingrong Sun ${ }^{1,2}$, \\ Yue Zhang ${ }^{3,4,5}$ and Xiaosheng Wang ${ }^{1,2 *}$ \\ ${ }^{1}$ Biomedical Informatics Research Lab, School of Basic Medicine and Clinical Pharmacy, China Pharmaceutical University, \\ Nanjing, China, ${ }^{2}$ Big Data Research Institute, China Pharmaceutical University, Nanjing, China, ${ }^{3}$ Pinghu Hospital of Shenzhen \\ University, Shenzhen, China, ${ }^{4}$ Futian Hospital for Rheumatic Diseases, Shenzhen, China, ${ }^{5}$ Department of Rheumatology and \\ Immunology, The First Clinical College of Harbin Medical University, Harbin, China
}

Background: Limited data on the efficacy and safety of currently applied COVID-19 therapeutics and their impact on COVID-19 outcomes have raised additional concern.

Objective and Methods: To estimate the efficacy and safety of COVID-19 therapeutics, we performed meta-analyses of the studies reporting clinical features and treatments of COVID-19 published from January 21 to September 6, 2020.

Results: We included 136 studies that involved 102,345 COVID-19 patients. The most prevalent treatments were antibiotics (proportion: $0.59,95 \% \mathrm{Cl}:[0.51,0.67])$ and antivirals (proportion: $0.52,95 \% \mathrm{Cl}$ [ $[0.44,0.60])$. The combination of lopinavir/ritonavir and Arbidol was the most effective in treating COVID-19 (standardized mean difference (SMD) $=0.68$, $95 \% \mathrm{Cl}:[0.15,1.21])$. The use of corticosteroids was associated with a small clinical improvement (SMD $=-0.40,95 \% \mathrm{Cl}:[-0.85,-0.23])$, but with a higher risk of disease progression and death (mortality: $\mathrm{RR}=9.26,95 \% \mathrm{Cl}$ : [4.81, 17.80]; hospitalization length: $R R=1.54,95 \% \mathrm{Cl}:[1.39,1.72]$; severe adverse events: $\mathrm{RR}=2.65,95 \% \mathrm{Cl}:[2.09,3.37])$. The use of hydroxychloroquine was associated with a higher risk of death $(R R=1.68,95 \%$ $\mathrm{Cl}$ : $[1.18,2.38])$. The combination of lopinavir/ritonavir, ribavirin, and interferon- $\beta(\mathrm{RR}=$ $0.34,95 \% \mathrm{Cl}:[0.22,0.54])$; hydroxychloroquine $(\mathrm{RR}=0.58,95 \% \mathrm{Cl}$ : [0.39, 0.58]); and lopinavir/ritonavir $(\mathrm{RR}=0.72,95 \% \mathrm{Cl}$ : $[0.56,0.91])$ was associated with reduced hospitalization length. Hydrocortisone $(\mathrm{RR}=0.05,95 \% \mathrm{Cl}$ : $[0.03,0.10])$ and remdesivir $(\mathrm{RR}=0.74,95 \% \mathrm{Cl}:[0.62,0.90])$ were associated with lower incidence of severe adverse events. Dexamethasone was not significant in reducing disease progression $(R R=0.45$, 95\% Cl: $[0.16,1.25])$ and mortality (RR $=0.90,95 \% \mathrm{Cl}:[0.70,1.16])$. The estimated combination of corticosteroids with antivirals was associated with a better clinical improvement than antivirals alone (SMD $=-1.09,95 \% \mathrm{Cl}:[-1.64,-0.53])$.

Conclusion: Antivirals are safe and effective in COVID-19 treatment. Remdesivir cannot significantly reduce COVID-19 mortality and hospitalization length, while it is associated with a lower incidence of severe adverse events. Corticosteroids could increase COVID-19 
severity, but it could be beneficial when combined with antivirals. Our data are potentially valuable for the clinical treatment and management of COVID-19 patients.

Keywords: COVID-19 treatment, meta-analysis, antiviral agents, hydroxychloroquine, dexamethasone, remdesivir

\section{INTRODUCTION}

Since the outbreak of coronavirus disease 2019 (COVID-19) caused by severe acute respiratory syndrome coronavirus 2 (SARS-CoV-2) in December 2019, more than 30 million cases and 945,000 deaths have been reported as of September 17, 2020, in the world (Johns Hopkins University, 2020). Compared to other beta coronaviruses that have caused epidemics over the last 2 decades, including severe acute respiratory syndrome coronavirus (SARS-CoV) and Middle East respiratory syndrome coronavirus (MERS-CoV), SARS-CoV-2 exhibits higher infectivity while lower fatality that makes it more destructive (Abdelrahman et al., 2020a). The rapid development of effective treatment approaches for COVID-19 is urgently needed since there is no specific therapy or vaccine for COVID-19. Previous experiences from SARS and MERS treatments suggested that several interventions, including antivirals, such as lopinavir/ritonavir and umifenovir, corticosteroids, interferons, ribavirin, and newly introduced drugs, including chloroquine or its derivative hydroxychloroquine, dexamethasone, and convalescent plasma, may improve clinical outcomes in COVID-19 patients, whereas the related data are not conclusive. Since the evidence of the efficacy and safety of these treatments remains lacking, we conducted meta-analyses of the therapeutic approaches for COVID-19 patients. Our meta-analyses aimed to identify the positive benefits (such as clinical improvement) and negative risks (such as long duration of hospitalization, severe adverse events, and increased deaths) of treatment strategies for COVID-19 by comparing different treatments using different meta-analysis models. The clinical improvement of patients is referred to as the negative conversion of RT-PCR (viral loads) within 14 days or discharged alive from the hospital. On the other hand, severe side effects are referred to as shock, acute respiratory syndrome, acute kidney injury, cardiac injury, or respiratory failure.

First, we conducted a proportional meta-analysis to summarize the pooled effect of the weighted consumption proportion of each treatment. Next, we identified the relative mortality risk of patients with the treatment vs. without the treatment. Finally, we conducted the network meta-analysis to compare different treatments directly and indirectly in clinical improvement and relative mortality risk or disease progression. We summarized available randomized and non-randomized clinical trials of several treatment strategies and provided point estimates and their 95\% confidence intervals (CIs) for the associations between these treatment strategies and given endpoints.

\section{METHODS}

\section{Search Strategy and Selection Criteria}

We performed this study according to the Preferred Reporting Items for Systematic reviews and Meta-Analyses recommendations "PRISMA" (PRISMA, 2015) (Figure 1 and Supplementary Table S1). We searched for publications between January 21, 2020, and September 6, 2020, in databases of PubMed, EMBASE, CNKI, Wanfang, Cochrane library, ClinicalTrials.gov, Scopus, Web of Science, Lancet, the New England Journal of Medicine, and JAMA COVID-19 platforms. We used the search term "2019 novel coronavirus, COVID-19 and SARS-CoV-2" AND "treatment, clinical characteristics, epidemiological characteristics, clinical trials, cohort studies, observational studies, case series" without language and age restriction. Search results were limited to the references published since January 21, 2020. We removed duplicate or irrelevant articles using the EndNote X9.0 software. To identify missed studies, we thoroughly checked the reference list for each selected article. Two reviewers independently screened the titles and abstracts of all references based on certain inclusion and exclusion criteria. The included studies involved the following information: clinical features, laboratory findings, and treatment approaches for COVID-19 patients with clinically defined outcomes. We excluded the following studies: 1) duplicate publications, preprints, reviews, case reports, family-based studies, unrelated titles or abstracts, studies not involving clinical features, laboratory findings, and treatment approaches, and 2) animal or in vitro studies. All the included studies had no restriction of age, area, and language. Two reviewers compared their screening results and discussed the differences. An agreement was reached through discussion.

\section{Data Extraction}

Two investigators (QL and SJ) performed a literature search and data extraction, and another investigator (ZA) resolved the disagreements. We extracted the following variables: author, date, age, gender, and number of participants in different groups for comparisons, including non-survival vs. survival, treatment vs. nontreatment. The extracted data included publication date, country, study design, number of enrolled subjects, data collection method, baseline characteristics before treatment, diagnostic method, population, COVID-19 treatment details, time from admission to starting treatment, and patient outcomes.

\section{Data Analyses}

This study performed three types of meta-analysis. First, a proportional meta-analysis by using the restricted maximum likelihood random-effect model (REML). We normalized proportional data by double-arcsine or logit transformation and confirmed their normal distribution by the Shapiro-Wilk test. Leave-one-out (LOO) analyses were performed to determine influential outliers in the proportional metaanalysis. Second, a meta-analysis of mortality risk using the Mantel-Haenszel random-effect model. Finally, a network 


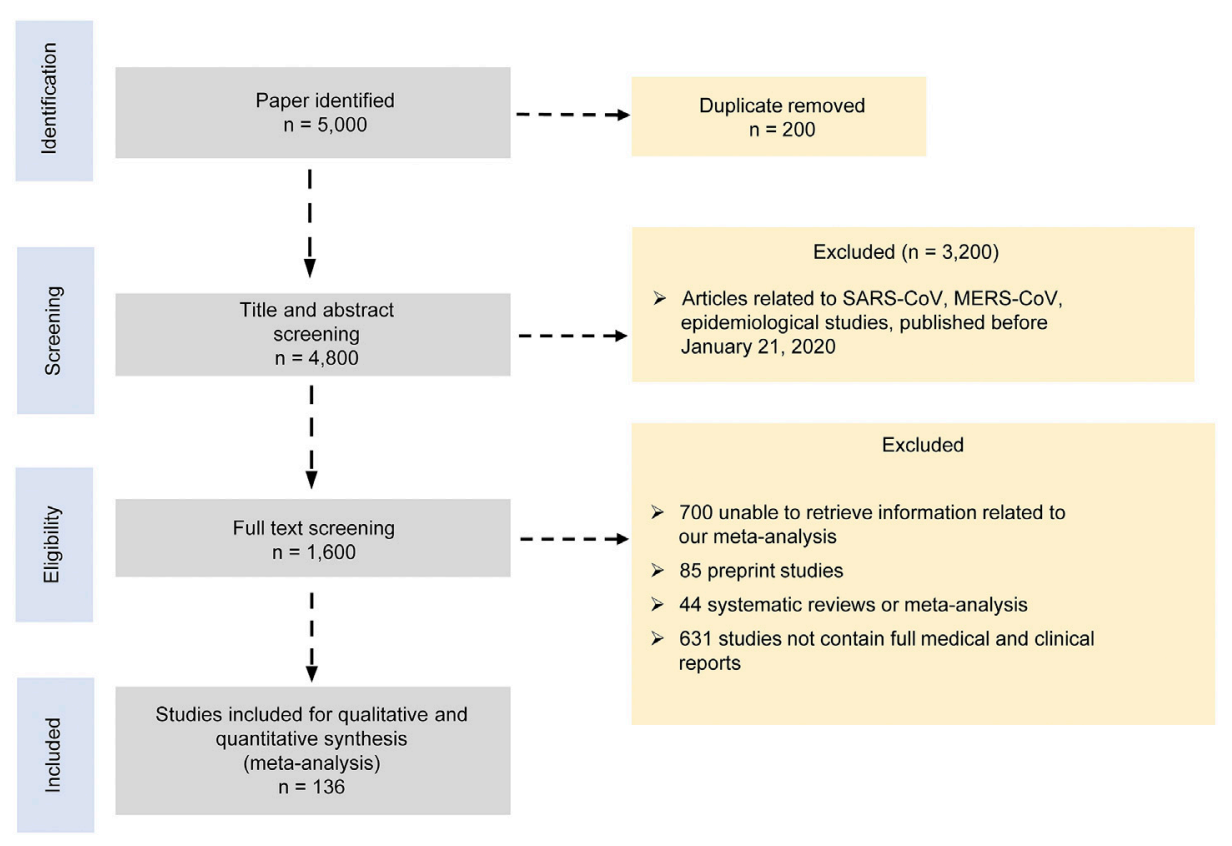

FIGURE 1 | PRISMA 2009 flow diagram.

meta-analysis evaluates direct and indirect relationships between different treatment strategies based on a common comparator, such as standard care. Standard care is defined here as supplementary oxygen, noninvasive and invasive ventilation, antibiotics, vasopressor support, RRT, and extracorporeal membrane oxygenation (Cao et al., 2020a). We estimated network meta-analysis models within a frequentist framework. We defined the clinical improvement, disease severity, and mortality as dichotomous variables and the duration of hospitalization as a continuous variable. We calculated the effect size of risk ratios (RRs) for negative outcomes and Hedges'g effect size, known as standardized mean difference (SMD), for positive outcomes with their $95 \%$ confidence intervals (CIs). The SMD results were defined as follows: small effect $\geq 0.2$, medium effect $\geq 0.5$, and large effect $\geq 0.8$. We generated publication bias funnel plots by scatterplot of study effect estimates on the $x$-axis (transformed proportion or RR) against study size on the $y$-axis (standard error). The two limit lines indicate the 95\% CI around the summary effect size. Egger's test metaregression model was used to detect funnel plot asymmetry.

Since there was clinical and methodological heterogeneity in study designs, interventions, and outcome measures, and participants' characteristics, a random-effect model was adopted in meta-analyses. Additionally, the Sidik-Jonkman estimator, $\mathrm{tau}^{2}$, and the confidence interval of $\operatorname{tau}^{2}$ were used. The Hartung-Knapp method was used to adjust for the randomeffect model. $I^{2}$ statistic and Cochran's Q test were used to assess statistical heterogeneity/inconsistency among meta-analysis models with a threshold of $\mathrm{I}^{2}>50 \%$ or $p \leq 0.05$. We performed meta-analyses using $\mathrm{R}$ packages "meta, netmeta, dmetar, and metafor" (Wang, 2018).

\section{Study Selection and Risk of Bias Assessment}

We assessed the risk of bias for eligible observational studies, such as cross-sectional, cohort studies, and case series, following the Strengthening the Reporting of Observational Studies in Epidemiology (STROBE) reporting guidelines (von Elm et al., 2007). We assessed the risk of bias in randomized control trials using the Cochrane risk-of-bias tool for randomized trials (ROB2) (Higgins et al., 2011). Two investigators (QL and SJ) conducted both risks of bias evaluations independently. Each assigned an overall risk of bias to each eligible study and consulted a third reviewer (ZA) if they disagreed. We summarized the results in Supplementary Figure S1.

\section{RESULTS}

We initially identified 5,000 articles based on our search criteria, most of which were irrelevant to our research objective or without published results (Figure 1). Finally, we included 136 articles in our meta-analysis, which involved a total of 102,345 subjects (Alam et al., 2020; Almazeedi et al., 2020; Asai et al., 2020; Bakhshaliyev et al., 2020; Beigel et al., 2020; Berenguer et al., 2020; Bhandari et al., 2020; Bhatraju et al., 2020; Boulware et al., 2020; Buckner et al., 2020; Cai et al., 2020; Campochiaro et al., 2020; Cao et al., 2020a; Cao et al., 2020b; Capone et al., 2020; Casas-Rojo et al., 2020; Catteau et al., 2020; Chen et al., 2020a; Chen et al., 2020b; Chen et al., 2020c; Chen et al., 2020d; Chen Jun et al., 2020; Colaneri et al., 2020; Deng et al., 2020; Dequin et al., 2020; Di Lorenzo et al., 2020; Fauvel et al., 2020; Ferrando et al., 2020; Fried et al., 2020; García-Salido et al., 2020; Gautret et al., 
2020; Geleris et al., 2020; Grein et al., 2020; Guervilly et al., 2020; Gupta et al., 2020; Han et al., 2020; Heffler et al., 2020; Hong et al., 2020; Hu et al., 2020a; Hu et al., 2020b; Huang et al., 2020a; Huang et al., 2020b; Huang et al., 2020c; Hung et al., 2020; Hur et al., 2020; Jacobs et al., 2020; Jiang et al., 2020; Karolyi et al., 2020; Kaushik et al., 2020; Khamis et al., 2020; Kim et al., 2020a; Kim et al., 2020b; Koleilat et al., 2020; Krishnan et al., 2020; Lecronier et al., 2020; Lee et al., 2020a; Lee et al., 2020b; Lendorf et al., 2020; Li et al., 2020a; Li et al., 2020b; Liabeuf et al., 2020; Lian et al., 2020a; Lian et al., 2020b; Liu et al., 2020a; Liu et al., 2020b; Liu et al., 2020c; Liu et al., 2020d; Lo et al., 2020; Lokken et al., 2020; Lovato et al., 2020; Maeda et al., 2020; Mahmoudi et al., 2020; Mikami et al., 2020; Mo et al., 2020; Monfared et al., 2020; Montastruc et al., 2020; Montero et al., 2020; Morena et al., 2020; Moreno-Pérez et al., 2020; Morrison et al., 2020; Mostaza et al., 2020; Myers et al., 2020; Nguyen et al., 2020; Nowak et al., 2020; Okoh et al., 2020; Ouyang et al., 2020; Palmieri et al., 2020; Pan et al., 2020; Pasquini et al., 2020; Pelayo et al., 2020; Piva et al., 2020; Potere et al., 2020; Price et al., 2020; Primmaz et al., 2020; Quartuccio et al., 2020; Richardson et al., 2020; Recovery Collaborative Group, 2020; Rosenberg et al., 2020; Salacup et al., 2020; Saleh et al., 2020; Sentilhes et al., 2020; Shah et al., 2020; Shekerdemian et al., 2020; Shi et al., 2020; Singh et al., 2020b; Skipper et al., 2020; Spinner et al., 2020; Suleyman et al., 2020; Tang et al., 2020; The Writing Committee for the REMAP-CAP Investigators, 2020; Tomazini et al., 2020; Toniati et al., 2020; Vahidy et al., 2020; Wang et al., 2020a; Wang et al., 2020b; Wang et al., 2020d; Wang et al., 2020e; Wu et al., 2020a; Wu et al., 2020b; Wu et al., 2020c; Xu et al., 2020a; Xu et al., 2020b; Xu et al., 2020c; Yan et al., 2020a; Yan et al., 2020b; Yang et al., 2020; Yu et al., 2020a; Yu et al., 2020b; Zerah et al., 2020; Zhang et al., 2020a; Zhang et al., 2020b; Zhang et al., 2020c; Zhao et al., 2020; Zheng et al., 2020; Zhou et al., 2020; Zhu et al., 2020).

\section{Characteristics of the Included Studies}

The 136 studies, which involved 102,345 patients, included 97 observational studies, 11 case series, five letters, one application note, 13 randomized trials, one pilot study, five reports, one nonrandomized trial, one short communication, and one correspondence. The countries involved in these studies included China (51 studies (Cai et al., 2020; Cao et al., 2020a; Cao et al., 2020b; Chen et al., 2020a; Chen et al., 2020b; Chen et al., 2020c; Chen et al., 2020d; Chen Jun et al., 2020; Deng et al., 2020; Hu et al., 2020a; Hu et al., 2020b; Huang et al., 2020a; Huang et al., 2020b; Huang et al., 2020c; Hung et al., 2020; Jiang et al., 2020; Li et al., 2020a; Li et al., 2020b; Lian et al., 2020a; Lian et al., 2020b; Liu et al., 2020a; Liu et al., 2020b; Liu et al., 2020c; Liu et al., 2020d; Mo et al., 2020; Ouyang et al., 2020; Pan et al., 2020; Shi et al., 2020; Tang et al., 2020; Wang et al., 2020a; Wang et al., 2020b; Wang et al., 2020d; Wang et al., 2020e; Wu et al., 2020a; Wu et al., 2020b; Wu et al., 2020c; Xu et al., 2020a; Xu et al., 2020b; Xu et al., 2020c; Yan et al., 2020a; Yan et al., 2020b; Yang et al., 2020; Yu et al., 2020a; Yu et al., 2020b; Zhang et al., 2020a; Zhang et al., 2020b; Zhang et al., 2020c; Zhao et al., 2020; Zheng et al., 2020; Zhou et al., 2020; Zhu et al., 2020)), the United States (31 studies (Alam et al., 2020; Bhatraju et al., 2020;
Buckner et al., 2020; Capone et al., 2020; Fried et al., 2020; Geleris et al., 2020; Grein et al., 2020; Gupta et al., 2020; Hur et al., 2020; Jacobs et al., 2020; Kaushik et al., 2020; Kim et al., 2020a; Koleilat et al., 2020; Krishnan et al., 2020; Lokken et al., 2020; Maeda et al., 2020; Mikami et al., 2020; Morrison et al., 2020; Myers et al., 2020; Okoh et al., 2020; Pelayo et al., 2020; Price et al., 2020; Richardson et al., 2020; Rosenberg et al., 2020; Salacup et al., 2020; Saleh et al., 2020; Shah et al., 2020; Shekerdemian et al., 2020; Singh et al., 2020b; Suleyman et al., 2020; Vahidy et al., 2020)), France (10 studies (Dequin et al., 2020; Fauvel et al., 2020; Gautret et al., 2020; Guervilly et al., 2020; Lecronier et al., 2020; Liabeuf et al., 2020; Montastruc et al., 2020; Nguyen et al., 2020; Sentilhes et al., 2020; Zerah et al., 2020)), Italy (12 studies (Campochiaro et al., 2020; Colaneri et al., 2020; Di Lorenzo et al., 2020; Heffler et al., 2020; Lovato et al., 2020; Morena et al., 2020; Palmieri et al., 2020; Pasquini et al., 2020; Piva et al., 2020; Potere et al., 2020; Quartuccio et al., 2020; Toniati et al., 2020)), Korea (four studies (Han et al., 2020; Hong et al., 2020; Kim et al., 2020b; Lee et al., 2020a)), Kuwait (one study (Almazeedi et al., 2020)), Japan (one study (Asai et al., 2020)), Turkey (one study (Bakhshaliyev et al., 2020)), Spain (seven studies (Berenguer et al., 2020; Casas-Rojo et al., 2020; Ferrando et al., 2020; García-Salido et al., 2020; Montero et al., 2020; Moreno-Pérez et al., 2020; Mostaza et al., 2020)), India (one study (Bhandari et al., 2020)), Canada (one study (Boulware et al., 2020)), Belgium (one study (Catteau et al., 2020)), Oman (one study (Khamis et al., 2020)), Singapore (one study (Lee et al., 2020b)), Denmark (one study (Lendorf et al., 2020)), Iran (two studies (Mahmoudi et al., 2020; Monfared et al., 2020)), United Kingdom (one study (Recovery Collaborative Group, 2020)), Switzerland (two studies (Pellaud et al., 2020; Primmaz et al., 2020)), Poland (one study (Nowak et al., 2020)), Brazil (one study (Tomazini et al., 2020)), Macau (one study (Lo et al., 2020)), Austria (one study (Karolyi et al., 2020)), and three studies (Beigel et al., 2020; Spinner et al., 2020; The Writing Committee for the REMAP-CAP Investigators, 2020) from multiple countries. A detailed description of these studies is shown in Supplementary Table S2.

Of the 136 studies, 45 reported antibiotics as one of the main treatment strategies for COVID-19, 58 for antivirals, 43 for corticosteroids, 27 for chloroquine or hydroxychloroquine, 19 for immunoglobulins, nine for interferons, 15 for RRT, 14 for tocilizumab, and less than five for IL-6 antagonist, immunomodulators, or immune enhancers. This study focused on evaluating the frequently used treatment strategies, including antibiotics, antivirals, corticosteroids, chloroquine or hydroxychloroquine, tocilizumab, interferons, immunoglobulins, and RRT.

\section{Proportional Meta-analysis}

First, we performed a proportional meta-analysis to estimate binomial (weighted) consumption proportions of each treatment. We obtained the average of the proportions of multiple studies weighted by the inverse of their sampling variances using the random-effect model. The sample sizes in these studies ranged from 7 to 15,111 , with a total number of 102,345 . The high prevalence was observed in antibiotics (proportion: $0.59,95 \%$ CI: $[0.51,0.67]$ ) and antivirals 


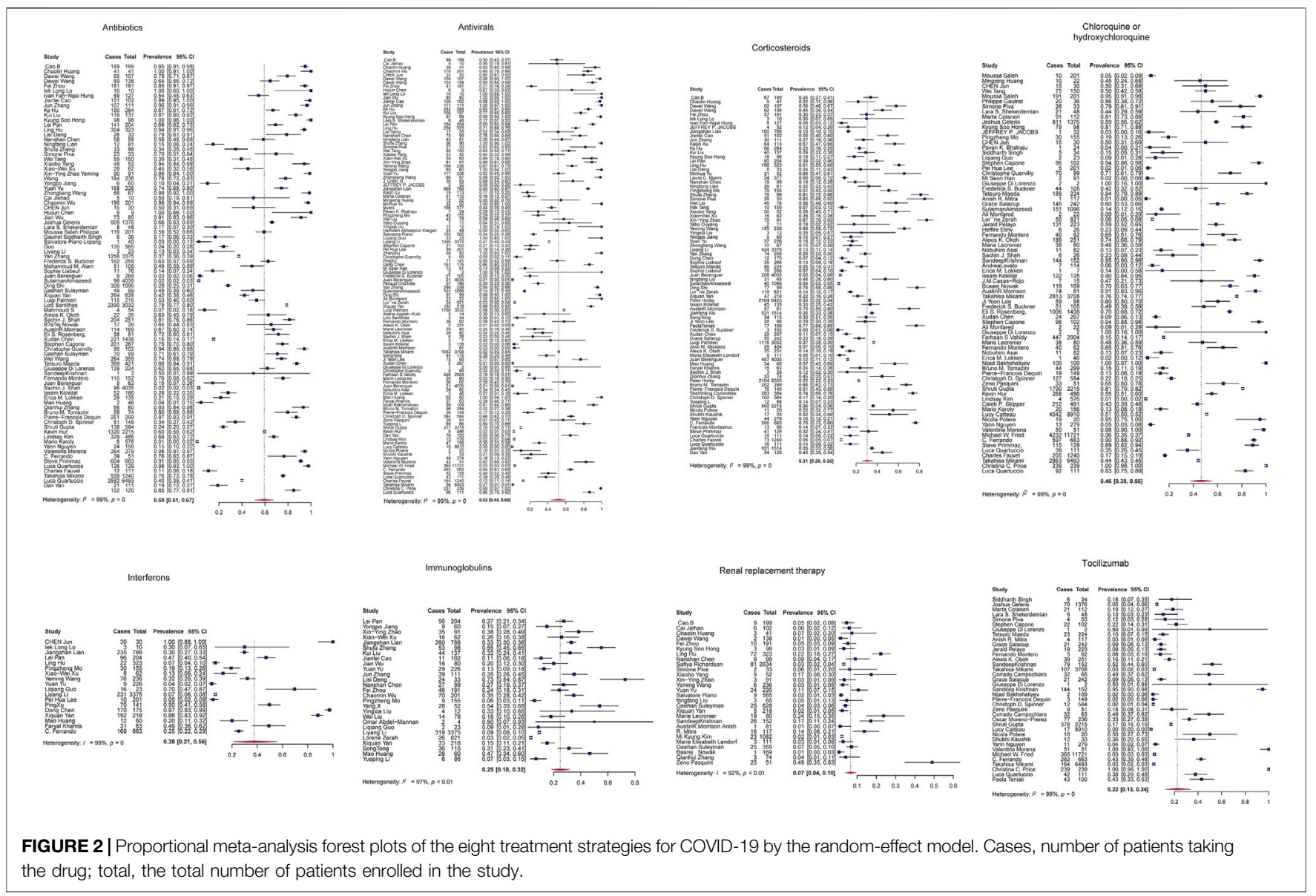

(proportion: 0.52, 95\% CI: [0.44, 0.60]) (Figure 2). We showed the results of proportional meta-analysis heterogeneity in Supplementary Table S3.

To determine whether outliers were influencing the proportional analysis results, we performed leave-one-out (LOO) analyses. We found six of the eight models having significant outliers, including antibiotics, antivirals, chloroquine or hydroxychloroquine, corticosteroids, interferons, and tocilizumab. Immunoglobulins and RRT models did not show any significant outliers (Supplementary Figures S2, S3). Finally, we assessed the potential publication bias in each treatment model using a funnel plot of the mixed-effect meta-regression model and the Egger's regression test with the standard error as a predictor. The funnel plots were roughly symmetrical in antibiotics, antivirals, chloroquine or hydroxychloroquine, interferons, and tocilizumab $(p>0.05)$. In contrast, Egger's test was significant in three treatment models: corticosteroids, immunoglobulins, and RRT $(p<0.05$; Supplementary Figure S4).

Second, to estimate the association between each treatment and COVID-19 mortality, we performed a meta-analysis of mortality risk using the Mantel-Haenszel random-effect model to quantify each drug effect on COVID-19 mortality. We used the general term "relative risk" to refer to the mortality risk. A total of 16 observational studies (Berenguer et al., 2020; Cao et al., 2020b;
Catteau et al., 2020; Ferrando et al., 2020; Gupta et al., 2020; Krishnan et al., 2020; Lee et al., 2020a; Morrison et al., 2020; Nowak et al., 2020; Okoh et al., 2020; Primmaz et al., 2020; Salacup et al., 2020; Wang et al., 2020a; Yan et al., 2020b; Zerah et al., 2020; Zhou et al., 2020) were involved in this assessment. We extracted the number of patients who died from COVID-19 following a certain treatment. We found that the use of interferons increases the risk of death $(\mathrm{RR}=1.30,95 \% \mathrm{CI}$ : $[1.02,1.65])$. In contrast, antibiotics, antivirals, chloroquine or hydroxychloroquine, corticosteroids, tocilizumab, RRT, and immunoglobulins did not show any significant impact on COVID-19 patients' mortality (Figure 3).

\section{Network Meta-Analysis}

For further validation, we compare the efficacy and safety of different anti-COVID-19 treatments by a network meta-analysis, which included 20 studies (Beigel et al., 2020; Cao et al., 2020a; Deng et al., 2020; Dequin et al., 2020; Gautret et al., 2020; Geleris et al., 2020; Huang et al., 2020b; Hung et al., 2020; Karolyi et al., 2020; Lecronier et al., 2020; Lian et al., 2020b; Recovery Collaborative Group, 2020; Skipper et al., 2020; Spinner et al., 2020; Tang et al., 2020; The Writing Committee for the REMAP-CAP Investigators, 2020; Tomazini et al., 2020; Wang et al., 2020d; Wu et al., 2020b; Zhu et al., 2020) (Supplementary

Table S4). These studies had identified treatment groups as drug 

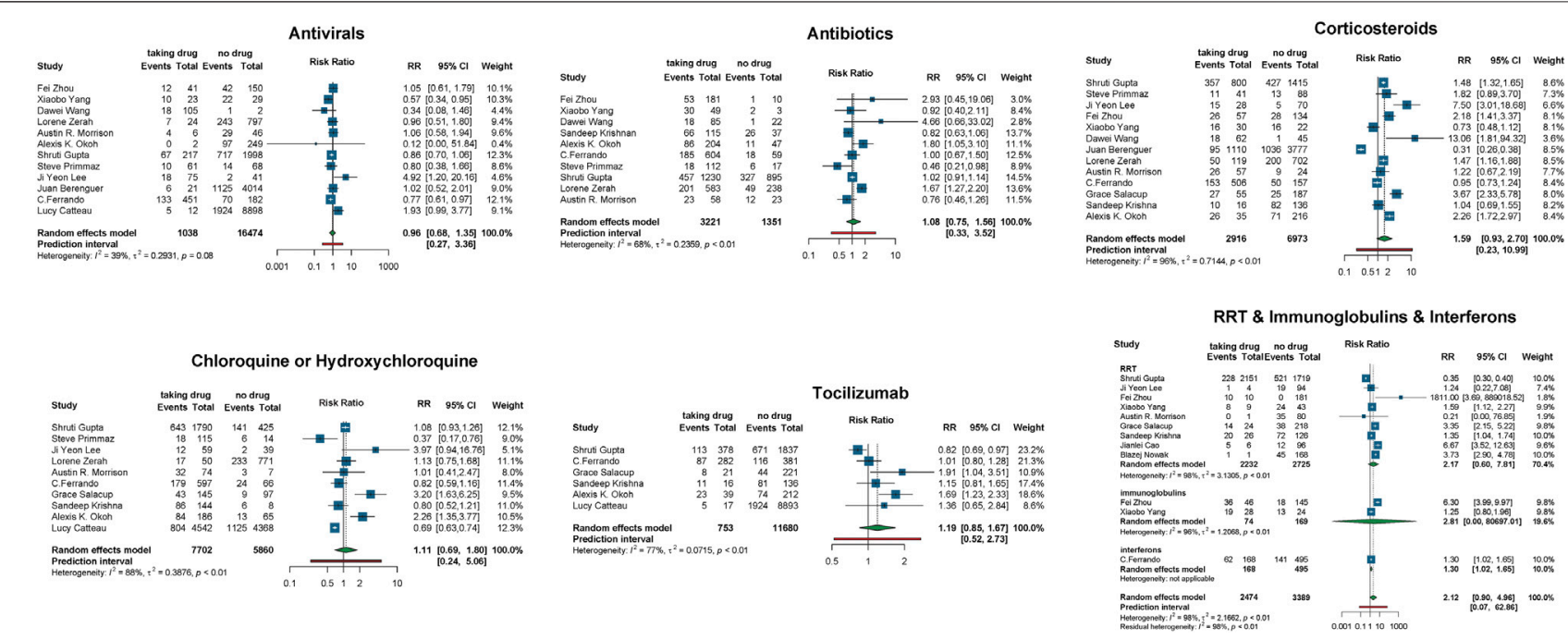

FIGURE 3 Relative mortality risk in COVID-19 patients receiving vs. not receiving therapy. Events, number of patients died from COVID-19; total, the total number of patients taking/not taking the drug; $\mathrm{RR}$, risk ratio; $\mathrm{Cl}$, confidence interval.

vs. standard care or standard treatments. First, we used the frequentist network model to define the effect size of each comparison as RR and the network inconsistency as the $\mathrm{Q}$ value. We did not observe any network inconsistency among our model $(0.46,95 \% \mathrm{CI}$ : $[0.00,0.75])$; heterogeneity within the design: $\mathrm{Q}=9.21, p=0.16$; heterogeneity between designs: $\mathrm{Q}=$ $5.62, p=0.06)$. Next, we estimated the efficacy and safety of each treatment relative to the standard care (Figure 4A). We found that the combination of lopinavir/ritonavir and Arbidol was significantly effective among COVID-19 treatments (SMD = $0.68,95 \%$ CI: $[0.15,1.21])$ compared to standard care. Arbidol, chloroquine or hydroxychloroquine, umifenovir, hydrocortisone, remdesivir, lopinavir/ritonavir, and the combination of lopinavir/ritonavir with ribavirin and interferon- $\beta$ showed no significant impact on clinical improvement compared to standard care (Figure 4B).

The use of corticosteroids was associated with a higher risk of disease progression and death (mortality: $\mathrm{RR}=9.26,95 \% \mathrm{CI}$ : [4.81, 17.80]; hospitalization length: $\mathrm{RR}=1.54,95 \% \mathrm{CI}$ : [1.39, 1.72]; severe side effect: $R R=2.65,95 \% \mathrm{CI}$ : [2.09, 3.37]), although it showed a small clinical improvement in COVID-19 patients $(\mathrm{SMD}=-0.40,95 \% \mathrm{CI}:[-0.85,-0.23])$. The use of hydroxychloroquine was also associated with a higher risk of death $(\mathrm{RR}=1.68,95 \% \mathrm{CI}:[1.18,2.38])$ than standard care. Remdesivir, lopinavir/ritonavir, and hydrocortisone showed no significant impact on reducing mortality risk compared to standard care (Figure 4B).

The combination of lopinavir/ritonavir, ribavirin, and interferon- $\beta \quad(\mathrm{RR}=0.34,95 \% \quad \mathrm{CI}: \quad[0.22,0.54])$, hydroxychloroquine $(\mathrm{RR}=0.58,95 \% \mathrm{CI}:[0.39,0.58])$, and lopinavir/ritonavir $(\mathrm{RR}=0.72,95 \% \mathrm{CI}:[0.56,0.91])$ was associated with reduced hospitalization length compared to standard care. The use of hydrocortisone $(\mathrm{RR}=6.38,95 \% \mathrm{CI}$ : $[4.91,8.31])$ was associated with prolonged hospitalization length compared to standard care. Remdesivir and umifenovir showed no significant impact on reducing hospitalization length compared to standard care (Figure $4 \mathrm{~B}$ ).

The use of hydrocortisone $(\mathrm{RR}=0.05,95 \% \mathrm{CI}:[0.03,0.10])$ and remdesivir $(\mathrm{RR}=0.74,95 \% \mathrm{CI}:[0.62,0.90])$ was associated with lower incidence of severe adverse events than standard care. The combination of lopinavir/ritonavir with ribavirin and interferon- $\beta$, besides the combination of lopinavir/ritonavir with Arbidol and hydroxychloroquine, showed no significant association with a lower or higher incidence of severe adverse events compared to standard care (Figure 4B).

Dexamethasone, a newly FDA approved corticosteroid for treating COVID-19, did not show any significant association with lower or higher incidence of severe adverse events $(\mathrm{RR}=0.45$, $95 \%$ CI: $[0.16,1.25])$, mortality $(\mathrm{RR}=0.90,95 \% \mathrm{CI}:[0.70,1.16])$, or clinical improvement (SMD $=-0.10,95 \% \mathrm{CI}$ : $[-0.05,0.25])$, compared to standard care (Figure 4B). Furthermore, we produced a matrix for the effect sizes of all possible treatment combinations. We estimated that the combination of lopinavir/ ritonavir and Arbidol with corticosteroids may be effective (SMD $=-1.09,95 \%$ CI: $[-1.64,-0.53])$. Besides, the combination of lopinavir/ritonavir and Arbidol (SMD $=-1.00,95 \% \mathrm{CI}$ : $[-1.73$, $-0.26]$ ) and lopinavir/ritonavir and dexamethasone (SMD = $-0.58,95 \%$ CI: $[-1.13,-0.03])$ may have resulted in a good clinical improvement (Figure 4C).

Since assessing the publication bias of a network meta-analysis in its aggregated form is problematic (Asai et al., 2020), we conducted an analysis called "comparison-adjusted funnel plot." We did not observe the funnel asymmetry (Egger's Test, $p=0.54$; Figure 4D).

\section{DISCUSSION AND CONCLUSION}

Currently, most of the COVID-19 treatments are symptomatic treatments. Treatments and oxygen therapy are the primary steps 


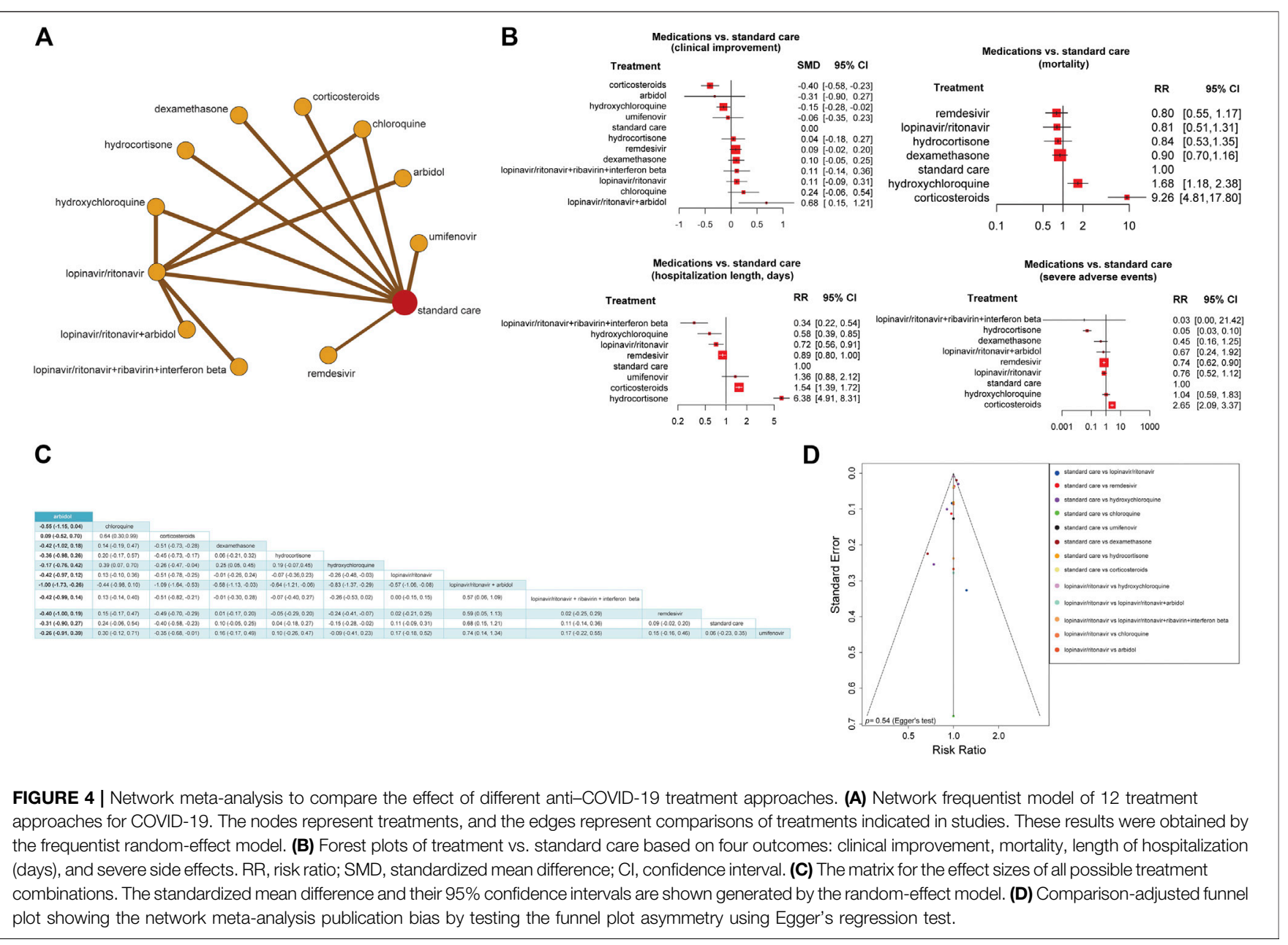

in addressing respiratory impairment in COVID-19 patients. Accumulating knowledge on the pathophysiology of lung damage provides clinicians with the strategies for dealing with respiratory failure caused by COVID-19 (Abdelrahman et al., 2020b). Several treatment attempts have become an essential part of COVID-19 treatment and management protocol, including antibiotics, antivirals, corticosteroids, interferons, RRT, chloroquine or hydroxychloroquine, dexamethasone, and tocilizumab, whereas there were no clear recommendations or rationale for using them. Earlier, 58\% of COVID-19 patients in Wuhan were treated with antibiotics, suspecting that lung inflammation is mostly correlated with bacterial infections. Later, the WHO recommended using empiric antibiotics against the bacterial superinfections of COVID-19 patients (Ginsburg and Klugman, 2020), although we did not find any significant impact of antibiotics on reducing mortality rates of COVID-19 patients.

During the SARS outbreak in 2004, serum concentrations of IL-6, IL-8, IL-16, and tumor necrosis factor- $\alpha$ were markedly upregulated in SARS patients (Gomersall, 2004). Since the median duration of ICU stays in SARS and COVID-19 patients ranged from 8 to 15 days, a logical scenario was introduced to modify the immune response with anti-inflammatory agents, such as corticosteroids (Gomersall, 2004). Although the data on the patients with acute respiratory distress syndrome (ARDS) showed that high-dose corticosteroids might have a beneficial effect, especially in mitigating the destructive inflammatory response in severe COVID-19 patients (Wu et al., 2020b), the rationale for using corticosteroids is still controversial due to their high adverse risk profile (Singh et al., 2020a). Recently, a few studies declared that dexamethasone could result in a lower risk of mortality than other corticosteroids or standard care (Recovery Collaborative Group, 2020; Tomazini et al., 2020). We found that corticosteroids were associated with a higher risk of disease progression and death than standard care and that dexamethasone neither significantly reduces severe side effects or mortality nor enhances clinical improvements compared to other corticosteroids or standard care.

Additionally, our results indicate that the use of corticosteroids has a positive impact on outcomes in COVID-19 patients compared to standard care, but the impact is minor. Furthermore, some reports stated that using corticosteroids in small doses could benefit COVID19 patients by mitigating inflammatory response (Wu et al., 2020 b), consistent with the results from our network analysis. 
However, the risk of using corticosteroids often outweighs its benefits (Wu et al., 2020b), especially in high doses, although the FDA has approved dexamethasone for COVID-19 treatment. Our results showed that dexamethasone had no significantly higher efficacy or safety than other drugs compared to standard care. Still, the combination of dexamethasone and antivirals could have more benefits for COVID-19 patients than dexamethasone alone, as suggested by our indirect treatment combination analysis (Figure 4C). Thus, corticosteroids could be beneficial in COVID-19 treatment if they combine in small doses with other drugs, although further clinical trials are needed to prove this.

The effectiveness of chloroquine or hydroxychloroquine against SARS-CoV-2 has been proposed in several studies (Bakhshaliyev et al., 2020; Boulware et al., 2020). Chloroquine and hydroxychloroquine are antimalarial drugs, which are also used for treating autoimmune diseases, such as systemic lupus erythematosus and rheumatoid arthritis (Bakhshaliyev et al., 2020; Boulware et al., 2020). In vitro studies showed that chloroquine and hydroxychloroquine could inhibit the fusion of SARS-CoV-2 with the host cell membranes by increasing the endosomal $\mathrm{pH}$ and interfere with the binding of SARS-CoV-2 to the cell receptor angiotensin-converting enzyme-2 (ACE2) by inhibiting its glycosylation (Sarayani et al., 2020). Although these studies have provided potential mechanisms of chloroquine and hydroxychloroquine in the treatment of COVID-19, the clinical evidence for their effectiveness remains lacking. Our results demonstrated that the use of hydroxychloroquine was associated with higher COVID-19 mortality risk, while it significantly reduced hospitalization length of COVID-19 patients compared to the standard care. This positive impact might be based on the prescribed dose or the patient's clinical status. However, one study in Belgium was conducted to evaluate the efficacy of low-dose hydroxychloroquine on COVID-19 mortality. They determined that a low-dose hydroxychloroquine was independently associated with lower mortality in hospitalized COVID-19 patients than standard care alone (Catteau et al., 2020). Another clinical trial was conducted on whether using hydroxychloroquine alone or with azithromycin could improve the clinical status of mild/ moderate COVID-19 patients within 15 days or not. The results revealed that there is no significant improvement in these patients within 15 days (Cavalcanti et al., 2020). Although the World Health Organization (WHO) recommends against using these drugs due to the limited evidence, most African countries are still utilizing them as the routine COVID-19 treatment (Belayneh, 2020).

Arbidol, a drug targeting influenza hemagglutinin (HA), was used in an early clinical trial of COVID-19 treatment (ChiCTR2000029573) and was consequently recommended in the Guidelines for the Diagnosis and Treatment of COVID-19 (sixth and seventh editions) in China (Wang et al., 2020c). Several studies have suggested that Arbidol could improve hospital discharge rate and reduce the risk of COVID-19 mortality (Li et al., 2020b; Deng et al., 2020). Likewise, lopinavir/ritonavir showed a broad safety profile, especially in mitigating disease progression and severity (Karolyi et al., 2020).
Our study showed that the combination of lopinavir/ritonavir and Arbidol was the most effective and safest among all COVID-19 treatments relative to the standard care. Also, the use of lopinavir/ritonavir significantly reduced hospitalization length compared to standard care. Remdesivir has been recognized as a promising antiviral drug against various RNA viruses, including SARS-CoV and MERS-CoV (Sheahan et al., 2017). However, its adverse effects have become a concern with its increased application in COVID-19 patients. Several studies have reported that remdesivir might increase liver injury (The COVID-19 Investigation Team, 2020), gastrointestinal discomfort (The COVID-19 Investigation Team, 2020), respiratory toxicity (Spinner et al., 2020), cardiovascular toxicity, and nephrotoxicity (Grein et al., 2020; Spinner et al., 2020). Recently, the WHO has issued a conditional recommendation against the use of remdesivir in hospitalized patients regardless of their disease severity, considering that there is no evidence that remdesivir can improve survival prognosis and other outcomes in COVID-19 patients (WHO, 2020). Our result demonstrated that using remdesivir was associated with a lower incidence of severe adverse events, whereas further clinical trials are required for validation of this result.

Since the outbreak of COVID-19, the guidelines and recommendations for COVID-19 treatment have been altered several times by the Centers for Disease Control and Prevention (CDC) and the National Institutes of Health (NIH). Since COVID-19 is often accompanied by organ damage caused by an inflated immune or inflammatory response to SARS-CoV-2 infection, the recommendations suggest that antiviral therapies would have the most significant effect for the early stage of COVID-19. For the late stage of COVID-19, immunosuppressive/anti-inflammatory treatments would be more effective. Nevertheless, currently, there are inadequate data from clinical trials for or against the use of a specific therapy. Hence, the COVID-19 Treatment Guidelines Panel keeps updating treatment recommendations for COVID-19 by reviewing the most recent clinical data (Nih Coronavirus Disease, 2019).

The study has several limitations. First, we may not include some relevant studies due to certain restrictions in searching for databases. Second, the quality of evidence is limited by data primarily derived from retrospective analyses, including heterogeneous data and study designs. Third, we could not conduct subgroup analyses due to the limited number of studies. Fourth, in some situations, we reported wide CIs because of clinical and methodological heterogeneity in studies, even when random-effect models were adopted. Finally, the number of randomized clinical trials included in network meta-analysis is limited, and thus further randomized trials are essential for validation and interpretation of the results.

In conclusion, this is the first systematic review, meta-analysis, and network meta-analysis of the efficacy and safety of eight COVID-19 therapeutic approaches. We believe that our study is potentially valuable for the clinical treatment and management of COVID-19 patients. This study performed three types of meta- 
analysis, namely, proportional meta-analysis to account for the average proportion of each treatment, mortality risk meta-analysis to estimate treatment risk on COVID-19 mortality, and network meta-analysis to compare the efficacy and safety of different COVID-19 treatments. Our results favor the routine use of antivirals against COVID-19 because of their wide safety and efficacy profiles, especially lopinavir/ritonavir without associations with disease progression and mortality. Our results did not support the routine use of remdesivir due to its uncertain safety and efficacy profiles. In addition, our results suggest that corticosteroids could increase COVID-19 severity, but it could be beneficial when combining with antivirals in small doses.

This systematic review and network meta-analysis would form part of a living or evolving meta-analysis or network metaanalysis and is required to be periodically updated as further new randomized trials that examined remdesivir, glucocorticoids, lopinavir/ritonavir, and chloroquine or hydroxychloroquine will be available soon.

\section{DATA AVAILABILITY STATEMENT}

The original contributions presented in the study are included in the article/Supplementary Material; further inquiries can be directed to the corresponding author.

\section{REFERENCES}

Abdelrahman, Z., Li, M., and Wang, X. (2020a). Comparative review of SARS$\mathrm{CoV}-2$, SARS-CoV, MERS-CoV, and influenza A respiratory viruses. Front. Immunol. 11, 552909. doi:10.3389/fimmu.2020.552909

Abdelrahman, Z., Liu, Q., Jiang, S., Li, M., Zhang, Y., and Wang, X. (2020b). Evaluation of the current therapeutic approaches for COVID-19: a meta-analysis. Available at: https://www.medrxiv.org/content/10.1101/2020.08.24.20180638v1.full.pdf.

Alam, M. M., Mahmud, S., Rahman, M. M., Simpson, J., Aggarwal, S., and Ahmed, Z. (2020). Clinical outcomes of early treatment with doxycycline for 89 highrisk COVID-19 patients in long-term care facilities in New York. Cureus 12, e9658. doi:10.7759/cureus.9658

Almazeedi, S., Al-Youha, S., Jamal, M. H., Al-Haddad, M., Al-Muhaini, A., AlGhimlas, F., et al. (2020). Characteristics, risk factors and outcomes among the first consecutive 1096 patients diagnosed with COVID-19 in Kuwait. EClinicalMedicine 24, 100448. doi:10.1016/j.eclinm.2020.100448

Asai, N., Sakanashi, D., Nakamura, A., Kishino, T., Kato, H., Hagihara, M., et al. (2020). Clinical manifestations and radiological features by chest computed tomographic findings of a novel coronavirus disease-19 pneumonia among 92 patients in Japan. J. Microbiol. Immunol. Infect. doi:10.1016/j.jmii.2020.07.011

Bakhshaliyev, N., Uluganyan, M., Enhos, A., Karacop, E., and Ozdemir, R. (2020). The effect of 5-day course of hydroxychloroquine and azithromycin combination on QT interval in non-ICU COVID19(+) patients. J. Electrocardiol. 62, 59-64. doi:10.1016/j.jelectrocard.2020.08.008

Beigel, J. H., Tomashek, K. M., Dodd, L. E., Mehta, A. K., Zingman, B. S., Kalil, A. C., et al. (2020). Remdesivir for the treatment of covid-19 - preliminary report. N Engl. J. Med. 383, 993-994. doi:10.1056/NEJMc2022236

Belayneh, A. (2020). Off-Label use of chloroquine and hydroxychloroquine for COVID-19 treatment in africa against WHO recommendation. Res. Rep. Trop. Med. 11, 61-72. doi:10.2147/RRTM.S269936

Berenguer, J., Ryan, P., Rodríguez-Baño, J., Jarrín, I., Carratalà, J., Pachón, J., et al. (2020). Characteristics and predictors of death among 4,035 consecutively hospitalized patients with COVID-19 in Spain. Clin. Microbiol. Infect. 26, 1525-1536. doi:10.1016/j.cmi.2020.07.024

\section{AUTHOR CONTRIBUTIONS}

Study design: ZA and XW; Data collection: ZA, QL, and SJ; Data analysis: ZA; Data interpretation: ZA, XW, YZ, QS, and ML; Visualization: ZA and ML; Manuscript drafting: ZA; Manuscript editing: XW; Study supervision: XW; Funding acquisition: QS and XW; Project administration: XW and ZA.

\section{FUNDING}

This work was supported by the China Pharmaceutical University, grant number 3150120001, to XW.

\section{ACKNOWLEDGMENTS}

This manuscript has been released as a preprint at medRxiv (Abdelrahman et al., 2020b).

\section{SUPPLEMENTARY MATERIAL}

The Supplementary Material for this article can be found online at: https://www.frontiersin.org/articles/10.3389/fphar.2021.607408/ full\#supplementary-material.

Bhandari, S., Singh, A., Sharma, R., Rankawat, G., Banerjee, S., Gupta, V., et al. (2020). Characteristics, treatment outcomes and role of hydroxychloroquine among 522 COVID-19 hospitalized patients in Jaipur city: an epidemio-clinical study. J. Assoc. Phys. India 68, 13-19.

Bhatraju, P. K., Ghassemieh, B. J., Nichols, M., Kim, R., Jerome, K. R., Nalla, A. K., et al. (2020). Covid-19 in critically ill patients in the Seattle region-case series. N. Engl. J. Med. 382, 2012-2022. doi:10.1056/NEJMoa2004500

Boulware, D. R., Pullen, M. F., Bangdiwala, A. S., Pastick, K. A., Lofgren, S. M., Okafor, E. C., et al. (2020). A randomized trial of hydroxychloroquine as postexposure prophylaxis for covid-19. N. Engl. J. Med. 383, 517-525. doi:10. 1056/NEJMoa2016638

Buckner, F. S., Mcculloch, D. J., Atluri, V., Blain, M., Mcguffin, S. A., Nalla, A. K., et al. (2020). Clinical features and outcomes of 105 hospitalized patients with COVID-19 in Seattle, Washington. Clin. Infect. Dis. 71, 2167-2173. doi:10. 1093/cid/ciaa632

Cai, J., Xu, J., Lin, D., Yang, Z., Xu, L., Qu, Z., et al. (2020). A case series of children with 2019 novel coronavirus infection: clinical and epidemiological features. Clin. Infect. Dis. 71, 1547-1551. doi:10.1093/cid/ciaa198

Campochiaro, C., Della-Torre, E., Cavalli, G., De Luca, G., Ripa, M., Boffini, N., et al. (2020). Efficacy and safety of tocilizumab in severe COVID-19 patients: a single-centre retrospective cohort study. Eur. J. Intern. Med. 76, 43-49. doi:10. 1016/j.ejim.2020.05.021

Cao, B., Wang, Y., Wen, D., Liu, W., Wang, J., Fan, G., et al. (2020a). A trial of lopinavir-ritonavir in adults hospitalized with severe covid-19. N. Engl. J. Med. 382, 1787-1799. doi:10.1056/NEJMoa2001282

Cao, J., Tu, W. J., Cheng, W., Yu, L., Liu, Y. K., Hu, X., et al. (2020b). Clinical features and short-term outcomes of 102 patients with corona virus disease 2019 in Wuhan, China. Clin. Infect. Dis. 71, 748-755. doi:10.1093/cid/ciaa243

Capone, S., Abramyan, S., Ross, B., Rosenberg, J., Zeibeq, J., Vasudevan, V., et al. (2020). Characterization of critically ill COVID-19 patients at a brooklyn safety-net hospital. Cureus 12, e9809. doi:10.7759/cureus.9809

Casas-Rojo, J. M., Antón-Santos, J. M., Millán-Núñez-Cortés, J., Lumbreras-Bermejo, C., Ramos-Rincón, J. M., Roy-Vallejo, E., et al. (2020). Clinical characteristics of patients hospitalized with COVID-19 in Spain: results from the SEMI-COVID-19 registry. Rev. Clin. Esp. 220, 480-494. doi:10.1016/j.rce.2020.07.003 
Catteau, L., Dauby, N., Montourcy, M., Bottieau, E., Hautekiet, J., Goetghebeur, E., et al. (2020). Low-dose hydroxychloroquine therapy and mortality in hospitalised patients with COVID-19: a nationwide observational study of 8075 participants. Int. J. Antimicrob. Agents 56, 106144. doi:10.1016/j. ijantimicag.2020.106144

Cavalcanti, A. B., Zampieri, F. G., Rosa, R. G., Azevedo, L. C. P., Veiga, V. C., Avezum, A., et al. (2020). Hydroxychloroquine with or without azithromycin in mild-to-moderate covid-19. N. Engl. J. Med. 383, e119. doi:10.1056/ NEJMx200021

Chen, D., Li, X., Song, Q., Hu, C., Su, F., Dai, J., et al. (2020a). Assessment of hypokalemia and clinical characteristics in patients with coronavirus disease 2019 in Wenzhou, China. JAMA Netw. Open 3, e2011122. doi:10.1001/ jamanetworkopen.2020.11122

Chen, H., Guo, J., Wang, C., Luo, F., Yu, X., Zhang, W., et al. (2020b). Clinical characteristics and intrauterine vertical transmission potential of COVID-19 infection in nine pregnant women: a retrospective review of medical records. Lancet 395, 809-815. doi:10.1016/S0140-6736(20)30360-3

Chen Jun, L. D., Liu, Li., Liu, Ping., Xu, Qingnian., Lu, Xia., Yun, Ling., et al. (2020). A pilot study of hydroxychloroquine in treatment of patients with common coronavirus disease-19 (COVID-19). J. Zhejiang. Univ. (Med. Sci.) 49, 215-219. doi:10.3785/j.issn.1008-9292.2020.03.03

Chen, N., Zhou, M., Dong, X., Qu, J., Gong, F., Han, Y., et al. (2020c). Epidemiological and clinical characteristics of 99 cases of 2019 novel coronavirus pneumonia in Wuhan, China: a descriptive study. Lancet 395, 507-513. doi:10.1016/S0140-6736(20)30211-7

Chen, X., Zhu, B., Hong, W., Zeng, J., He, X., Chen, J., et al. (2020d). Associations of clinical characteristics and treatment regimens with the duration of viral RNA shedding in patients with COVID-19. Int. J. Infect. Dis. 98, 252-260. doi:10. 1016/j.ijid.2020.06.091

Colaneri, M., Bogliolo, L., Valsecchi, P., Sacchi, P., Zuccaro, V., Brandolino, F., et al. (2020). Tocilizumab for treatment of severe COVID-19 patients: preliminary results from SMAtteo COvid19 REgistry (SMACORE). Microorganisms 8, 695. doi:10.3390/microorganisms 8050695

Deng, L., Li, C., Zeng, Q., Liu, X., Li, X., Zhang, H., et al. (2020). Arbidol combined with LPV/r versus LPV/r alone against Corona Virus Disease 2019: a retrospective cohort study. J. Infect. 81, e1-e5. doi:10.1016/j.jinf.2020.03.002

Dequin, P.-F., Heming, N., Meziani, F., Plantefève, G., Voiriot, G., Badié, J., et al. (2020). Effect of hydrocortisone on 21-day mortality or respiratory support among critically ill patients with COVID-19: a randomized clinical trial. JAMA 324, 1298-1306. doi:10.1001/jama.2020.16761

Di Lorenzo, G., Buonerba, L., Ingenito, C., Crocetto, F., Buonerba, C., Libroia, A., et al. (2020). Clinical characteristics of metastatic prostate cancer patients infected with COVID-19 in south Italy. Oncology 98, 743-747. doi:10.1159/ 000509434

Fauvel, C., Weizman, O., Trimaille, A., Mika, D., Pommier, T., Pace, N., et al. (2020). Pulmonary embolism in COVID-19 patients: a French multicentre cohort study. Eur. Heart J. 41, 3058-3068. doi:10.1093/eurheartj/ehaa500

Ferrando, C., Mellado-Artigas, R., Gea, A., Arruti, E., Aldecoa, C., Bordell, A., et al. (2020). Patient characteristics, clinical course and factors associated to ICU mortality in critically ill patients infected with SARS-CoV-2 in Spain: a prospective, cohort, multicentre study. Rev. Esp. Anestesiol. Reanim. 67, 425-437. doi:10.1016/j.redar.2020.07.003

Fried, M. W., Crawford, J. M., Mospan, A. R., Watkins, S. E., Munoz Hernandez, B., Zink, R. C., et al. (2020). Patient characteristics and outcomes of 11,721 patients with COVID19 hospitalized across the United States. Clin. Infect. Dis. 2020, ciaa1268. doi:10.1093/cid/ciaa1268

García-Salido, A., Leoz-Gordillo, I., Martínez De Azagra-Garde, A., Nieto-Moro, M., Iglesias-Bouzas, M. I., García-Teresa, M., et al. (2020). Children in critical care due to severe acute respiratory syndrome coronavirus 2 infection: experience in a Spanish hospital. Pediatr. Crit. Care Med. 21, e576-e580. doi:10.1097/PCC.0000000000002475

Gautret, P., Lagier, J. C., Parola, P., Hoang, V. T., Meddeb, L., Mailhe, M., et al. (2020). Hydroxychloroquine and azithromycin as a treatment of COVID-19: results of an open-label non-randomized clinical trial. Int. J. Antimicrob. Agents 56, 105949. doi:10.1016/j.ijantimicag.2020.105949

Geleris, J., Sun, Y., Platt, J., Zucker, J., Baldwin, M., Hripcsak, G., et al. (2020). Observational study of hydroxychloroquine in hospitalized patients with covid19. N. Engl. J. Med. 382, 2411-2418. doi:10.1056/NEJMoa2012410
Ginsburg, A. S., and Klugman, K. P. (2020). COVID-19 pneumonia and the appropriate use of antibiotics. Lancet Glob Health 8, e1453-e1454. doi:10.1016/ S2214-109X(20)30444-7

Gomersall, C. D. (2004). Pro/con clinical debate: steroids are a key component in the treatment of SARS. Pro: yes, steroids are a key component of the treatment regimen for SARS. Crit. Care 8, 105-107. doi:10.1186/cc2452

Grein, J., Ohmagari, N., Shin, D., Diaz, G., Asperges, E., Castagna, A., et al. (2020). Compassionate use of remdesivir for patients with severe covid-19. N. Engl. J. Med. 382, 2327-2336. doi:10.1056/NEJMoa2007016

Guervilly, C., Burtey, S., Sabatier, F., Cauchois, R., Lano, G., Abdili, E., et al. (2020). Circulating endothelial cells as a marker of endothelial injury in severe COVID -19. J. Infect. Dis. 103, 3603-3605. doi:10.1182/blood-2003-10-3479

Gupta, S., Hayek, S. S., Wang, W., Chan, L., Mathews, K. S., Melamed, M. L., et al. (2020). Factors associated with death in critically ill patients with coronavirus disease 2019 in the US. JAMA Intern. Med. 180, 1-12. doi:10.1001/ jamainternmed.2020.3596

Han, M. S., Choi, E. H., Chang, S. H., Jin, B. L., Lee, E. J., Kim, B. N., et al. (2020). Clinical characteristics and viral RNA detection in children with coronavirus disease 2019 in the Republic of Korea. JAMA Pediatr. 175, 73-80. doi:10.1001/ jamapediatrics.2020.3988

Heffler, E., Detoraki, A., Contoli, M., Papi, A., Paoletti, G., Malipiero, G., et al. (2020). COVID-19 in Severe Asthma Network in Italy (SANI) patients: clinical features, impact of comorbidities and treatments. Allergy 2020, 14532. doi:10. 1111/all.14532

Higgins, J. P. T., Altman, D. G., Gøtzsche, P. C., Jüni, P., Moher, D., Oxman, A. D., et al. (2011). The Cochrane collaboration's tool for assessing risk of bias in randomised trials. BMJ 343, d5928. doi:10.1136/bmj.d5928

Hong, K. S., Lee, K. H., Chung, J. H., Shin, K. C., Choi, E. Y., Jin, H. J., et al. (2020). Clinical features and outcomes of 98 patients hospitalized with SARS-CoV-2 infection in daegu, South Korea: a brief descriptive study. Yonsei Med. J. 61, 431-437. doi:10.3349/ymj.2020.61.5.431

Hu, K., Guan, W. J., Bi, Y., Zhang, W., Li, L., Zhang, B., et al. (2020a). Efficacy and safety of Lianhuaqingwen capsules, a repurposed Chinese herb, in patients with coronavirus disease 2019: A multicenter, prospective, randomized controlled trial. Phytomedicine 2020, 153242. doi:10.1016/j. phymed.2020.153242

Hu, L., Chen, S., Fu, Y., Gao, Z., Long, H., Wang, J. M., et al. (2020b). Risk factors associated with clinical outcomes in 323 COVID-19 hospitalized patients in Wuhan, China. Clin. Infect. Dis. 71, 2089-2098. doi:10.1093/cid/ciaa539

Huang, C., Wang, Y., Li, X., Ren, L., Zhao, J., Hu, Y., et al. (2020a). Clinical features of patients infected with 2019 novel coronavirus in Wuhan, China. Lancet 395, 497-506. doi:10.1016/S0140-6736(20)30183-5

Huang, M., Tang, T., Pang, P., Li, M., Ma, R., Lu, J., et al. (2020b). Treating COVID19 with chloroquine. J. Mol. Cell. Biol. 12, 322-325. doi:10.1093/jmcb/mjaa014

Huang, M., Yang, Y., Shang, F., Zheng, Y., Zhao, W., Luo, L., et al. (2020c). Clinical characteristics and predictors of disease progression in severe patients with COVID-19 infection in jiangsu province, China: a descriptive study. Am. J. Med. Sci. 360, 120-128. doi:10.1016/j.amjms.2020.05.038

Hung, I. F., Lung, K. C., Tso, E. Y., Liu, R., Chung, T. W., Chu, M. Y., et al. (2020). Triple combination of interferon beta-1b, lopinavir-ritonavir, and ribavirin in the treatment of patients admitted to hospital with COVID-19: an open-label, randomised, phase 2 trial. Lancet 395, 1695-1704. doi:10.1016/S0140-6736(20) $31042-4$

Hur, K., Price, C. P. E., Gray, E. L., Gulati, R. K., Maksimoski, M., Racette, S. D., et al. (2020). Factors associated with intubation and prolonged intubation in hospitalized patients with COVID-19. Otolaryngol. Head Neck Surg. 163, 170-178. doi:10.1177/0194599820929640

Jacobs, J. P., Stammers, A. H., St Louis, J., Hayanga, J. W. A., Firstenberg, M. S., Mongero, L. B., et al. (2020). Extracorporeal membrane oxygenation in the treatment of severe pulmonary and cardiac compromise in COVID-19: experience with 32 patients. ASAIO J. 66, 722-730. doi:10.1097/MAT. 0000000000001185

Jiang, Y., He, S., Zhang, C., Wang, X., Chen, X., Jin, Y., et al. (2020). Clinical characteristics of 60 discharged cases of 2019 novel coronavirus-infected pneumonia in Taizhou, China. Ann. Transl. Med. 8, 547. doi:10.21037/atm. 2020.04.20

Johns Hopkins University (2020). COVID-19 Map - Johns Hopkins Coronavirus Resource Center. Available: https://coronavirus.jhu.edu/map.html. 
Karolyi, M., Pawelka, E., Mader, T., Omid, S., Kelani, H., Ely, S., et al. (2020). Hydroxychloroquine versus lopinavir/ritonavir in severe COVID-19 patients : results from a real-life patient cohort. Wien Klin Wochenschr. 2020, 1-8. doi:10. 1007/s00508-020-01720-y

Kaushik, S., Aydin, S. I., Derespina, K. R., Bansal, P. B., Kowalsky, S., Trachtman, R., et al. (2020). Multisystem inflammatory syndrome in children associated with severe acute respiratory syndrome coronavirus 2 infection (MIS-C): a multi-institutional study from New York city. J. Pediatr. 224, 24-29. doi:10. 1016/j.jpeds.2020.06.045

Khamis, F., Al-Zakwani, I., Al Naamani, H., Al Lawati, S., Pandak, N., Omar, M. B., et al. (2020). Clinical characteristics and outcomes of the first 63 adult patients hospitalized with COVID-19: an experience from Oman. J. Infect. Public Health 13, 906-913. doi:10.1016/j.jiph.2020.06.002

Kim, L., Whitaker, M., O'halloran, A., Kambhampati, A., Chai, S. J., Reingold, A., et al. (2020a). Hospitalization rates and characteristics of children Aged< 18 Years hospitalized with laboratory-confirmed COVID-19-COVID-NET, 14 states. MMWR Morb. Mortal Wkly. Rep. 69, 1081. doi:10.15585/mmwr. $\mathrm{mm} 6932 \mathrm{e} 3$

Kim, M. K., Jeon, J. H., Kim, S. W., Moon, J. S., Cho, N. H., Han, E., et al. (2020b). The clinical characteristics and outcomes of patients with moderate-to-severe coronavirus disease 2019 infection and diabetes in daegu, South Korea. Diabetes Metab. J. 44, 602-613. doi:10.4093/dmj.2020.0146

Koleilat, I., Galen, B., Choinski, K., Hatch, A. N., Jones, D. B., Billett, H., et al. (2020). Clinical characteristics of acute lower extremity deep venous thrombosis diagnosed by duplex in patients hospitalized for coronavirus disease 2019. J. Vasc. Surg. Venous Lymphat. Disord. 9, 36-46. doi:10.1016/j. jvsv.2020.06.012

Krishnan, S., Patel, K., Desai, R., Sule, A., Paik, P., Miller, A., et al. (2020). Clinical comorbidities, characteristics, and outcomes of mechanically ventilated patients in the State of Michigan with SARS-CoV-2 pneumonia. J. Clin. Anesth. 67, 110005. doi:10.1016/j.jclinane.2020.110005

Lecronier, M., Beurton, A., Burrel, S., Haudebourg, L., Deleris, R., Le Marec, J., et al. (2020). Comparison of hydroxychloroquine, lopinavir/ritonavir, and standard of care in critically ill patients with SARS-CoV-2 pneumonia: an opportunistic retrospective analysis. Crit. Care 24, 418. doi:10.1186/s13054-020-03117-9

Lee, J. Y., Kim, H. A., Huh, K., Hyun, M., Rhee, J. Y., Jang, S., et al. (2020a). Risk factors for mortality and respiratory support in elderly patients hospitalized with COVID-19 in Korea. J. Korean Med. Sci. 35, e223. doi:10.3346/jkms.2020. 35.e223

Lee, P. H., Tay, W. C., Sutjipto, S., Fong, S. W., Ong, S. W. X., Wei, W. E., et al. (2020b). Associations of viral ribonucleic acid (RNA) shedding patterns with clinical illness and immune responses in Severe Acute Respiratory Syndrome Coronavirus 2 (SARS-CoV-2) infection. Clin. Transl. Immunol. 9, el160. doi:10.1002/cti2.1160

Lendorf, M. E., Boisen, M. K., Kristensen, P. L., Løkkegaard, E. C. L., Krog, S. M., Brandi, L., et al. (2020). Characteristics and early outcomes of patients hospitalised for COVID-19 in North Zealand, Denmark. Dan. Med. J. 67, A06200428.

Li, L., Huang, Q., Wang, D. C., Ingbar, D. H., Wang, X. J. C., and Medicine, T. (2020a). Acute lung injury in patients with COVID-19 infection. Clin. Transl. Med. 10, 20-27. doi:10.1002/ctm2.16

Li, Y., Xie, Z., Lin, W., Cai, W., Wen, C., Guan, Y., et al. (2020b). Efficacy and safety of lopinavir/ritonavir or arbidol in adult patients with mild/moderate COVID19: an exploratory randomized controlled trial. Med 1, 105-113. doi:10.1016/j. medj.2020.04.001

Liabeuf, S., Moragny, J., Bennis, Y., Batteux, B., Brochot, E., Schmit, J. L., et al. (2020). Association between renin-angiotensin system inhibitors and COVID19 complications. Eur. Heart J. Cardiovasc. Pharmacother. 2020, pvaa062. doi:10.1093/ehjcvp/pvaa062

Lian, J., Jin, X., Hao, S., Cai, H., Zhang, S., Zheng, L., et al. (2020a). Analysis of epidemiological and clinical features in older patients with corona virus disease 2019 (COVID-19) out of Wuhan. Clin. Infect. Dis. 2020, ciaa242. doi:10.1093/ cid/ciaa242

Lian, N., Xie, H., Lin, S., Huang, J., Zhao, J., and Lin, Q. (2020b). Umifenovir treatment is not associated with improved outcomes in patients with coronavirus disease 2019: a retrospective study. Clin. Microbiol. Infect. 26, 917-921. doi:10.1016/j.cmi.2020.04.026
Liu, F., Ji, C., Luo, J., Wu, W., Zhang, J., Zhong, Z., et al. (2020a). Clinical characteristics and corticosteroids application of different clinical types in patients with corona virus disease 2019. Sci. Rep. 10, 13689. doi:10.1038/ s41598-020-70387-2

Liu, K., Fang, Y.-Y., Deng, Y., Liu, W., Wang, M.-F., Ma, J.-P., et al. (2020b). Clinical characteristics of novel coronavirus cases in tertiary hospitals in Hubei Province. Chin. Med. J. 133, 1025-1031. doi:10.1097/CM1099. 0000000000000744

Liu, W., Tao, Z.-W., Wang, L., Yuan, M.-L., Liu, K., Zhou, L., et al. (2020c). Analysis of factors associated with disease outcomes in hospitalized patients with 2019 novel coronavirus disease. Chin. Med. J. 133, 1032-1038. doi:10.1097/CM9. 0000000000000775

Liu, Y., Yang, Y., Zhang, C., Huang, F., Wang, F., Yuan, J., et al. (2020d). Clinical and biochemical indexes from $2019-\mathrm{nCoV}$ infected patients linked to viral loads and lung injury. Sci. China Life Sci. 63, 364-374. doi:10.1007/s11427-0201643-8

Lo, I. L., Lio, C. F., Cheong, H. H., Lei, C. I., Cheong, T. H., Zhong, X., et al. (2020). Evaluation of SARS-CoV-2 RNA shedding in clinical specimens and clinical characteristics of 10 patients with COVID-19 in Macau. Int. J. Biol. Sci. 16, 1698-1707. doi:10.7150/ijbs. 45357

Lokken, E. M., Walker, C. L., Delaney, S., Kachikis, A., Kretzer, N. M., Erickson, A., et al. (2020). Clinical characteristics of 46 pregnant women with a severe acute respiratory syndrome coronavirus 2 infection in Washington State. Am. J. Obstet. Gynecol. 223, 911.e1-911.e14. doi:10.1016/j.ajog.2020.05.031

Lovato, A., Galletti, C., Galletti, B., and De Filippis, C. (2020). Clinical characteristics associated with persistent olfactory and taste alterations in COVID-19: a preliminary report on 121 patients. Am. J. Otolaryngol. 41, 102548. doi:10.1016/j.amjoto.2020.102548

Maeda, T., Obata, R., Rizk, D. D., and Kuno, T. (2020). The association of interleukin-6 value, interleukin inhibitors, and outcomes of patients with COVID-19 in New York City. J. Med. Virol. 93, 463-471. doi:10.1002/jmv. 26365

Mahmoudi, S., Mehdizadeh, M., Shervin Badv, R., Navaeian, A., Pourakbari, B., Rostamyan, M., et al. (2020). The coronavirus disease 2019 (COVID-19) in children: a study in an Iranian children's referral hospital. Infect Drug Resist 13, 2649-2655. doi:10.2147/IDR.S259064

Mikami, T., Miyashita, H., Yamada, T., Harrington, M., Steinberg, D., Dunn, A., et al. (2020). Risk factors for mortality in patients with COVID-19 in New York city. J. Gen. Intern. Med. 36, 17-26. doi:10.1007/s11606-020-05983-z

Mo, P., Xing, Y., Xiao, Y., Deng, L., Zhao, Q., Wang, H., et al. (2020). Clinical characteristics of refractory COVID-19 pneumonia in Wuhan, China. Clin. Infect. Dis. 2020, ciaa270. doi:10.1093/cid/ciaa270

Monfared, A., Dashti-Khavidaki, S., Jafari, R., Jafari, A., Ramezanzade, E., Lebadi, M. K., et al. (2020). Clinical characteristics and outcome of COVID-19 pneumonia in kidney transplant recipients in Razi hospital, Rasht, Iran. Transpl. Infect Dis. 22, e13420. doi:10.1111/tid.13420

Montastruc, F., Romano, C., Montastruc, J. L., Silva, S., Seguin, T., Minville, V., et al. (2020). Pharmacological characteristics of patients infected with SARScov-2 admitted to intensive care unit in south of France. Therapie 75, 381-384. doi:10.1016/j.therap.2020.05.005

Montero, F., Martínez-Barrio, J., Serrano-Benavente, B., González, T., Rivera, J., Molina Collada, J., et al. (2020). Coronavirus disease 2019 (COVID-19) in autoimmune and inflammatory conditions: clinical characteristics of poor outcomes. Rheumatol. Int. 40, 1593-1598. doi:10.1007/s00296-020-04676-4

Morena, V., Milazzo, L., Oreni, L., Bestetti, G., Fossali, T., Bassoli, C., et al. (2020). Off-label use of tocilizumab for the treatment of SARS-CoV-2 pneumonia in Milan, Italy. Eur. J. Intern. Med. 76, 36-42. doi:10.1016/j.jim.2020.05.011

Moreno-Pérez, O., Andres, M., Leon-Ramirez, J. M., Sánchez-Payá, J., Rodríguez, J. C., Sánchez, R., et al. (2020). Experience with tocilizumab in severe COVID19 pneumonia after 80 days of follow-up: a retrospective cohort study. J. Autoimmun. 114, 102523. doi:10.1016/j.jaut.2020.102523

Morrison, A. R., Johnson, J. M., Griebe, K. M., Jones, M. C., Stine, J. J., Hencken, L. N., et al. (2020). Clinical characteristics and predictors of survival in adults with coronavirus disease 2019 receiving tocilizumab. J. Autoimmun. 114, 102512. doi:10.1016/j.jaut.2020.102512

Mostaza, J. M., García-Iglesias, F., González-Alegre, T., Blanco, F., Varas, M., Hernández-Blanco, C., et al. (2020). Clinical course and prognostic factors of 
COVID-19 infection in an elderly hospitalized population. Arch. Gerontol. Geriatr. 91, 104204. doi:10.1016/j.archger.2020.104204

Myers, L. C., Parodi, S. M., Escobar, G. J., and Liu, V. X. (2020). Characteristics of hospitalized adults with COVID-19 in an integrated Health care system in California. JAMA 323, 2195-2198. doi:10.1001/jama.2020.7202

Nguyen, Y., Corre, F., Honsel, V., Curac, S., Zarrouk, V., Burtz, C. P., et al. (2020). A nomogram to predict the risk of unfavourable outcome in COVID-19: a retrospective cohort of 279 hospitalized patients in Paris area. Ann. Med. 52, 367-375. doi:10.1080/07853890.2020.1803499

Nih Coronavirus Disease (2019). (COVID-19) treatment guidelines. Available at: https://www.covid19treatmentguidelines.nih.gov/.

Nowak, B., Szymański, P., Pańkowski, I., Szarowska, A., Życińska, K., Rogowski, W., et al. (2020). Clinical characteristics and short-term outcomes of patients with coronavirus disease 2019: a retrospective single-center experience of a designated hospital in Poland. Pol. Arch. Intern. Med. 130, 407-411. doi:10. 20452/pamw.15361

Okoh, A. K., Sossou, C., Dangayach, N. S., Meledathu, S., Phillips, O., Raczek, C., et al. (2020). Coronavirus disease 19 in minority populations of Newark, New Jersey. Int. J. Equity Health 19, 93. doi:10.1186/s12939-020-01208-1

Ouyang, Y., Yin, J., Wang, W., Shi, H., Shi, Y., Xu, B., et al. (2020). Down-regulated gene expression spectrum and immune responses changed during the disease progression in COVID-19 patients. Clin. Infect Dis. 71, 2052-2060. doi:10.1093/ $\mathrm{cid} / \mathrm{ciaa} 462$

Palmieri, L., Vanacore, N., Donfrancesco, C., Lo Noce, C., Canevelli, M., Punzo, O., et al. (2020). Clinical characteristics of hospitalized individuals dying with COVID-19 by age group in Italy. J. Gerontol. A Biol. Sci. Med. Sci. 75, 1796-1800. doi:10.1093/gerona/glaal46

Pan, L., Mu, M., Yang, P., Sun, Y., Wang, R., Yan, J., et al. (2020). Clinical characteristics of COVID-19 patients with digestive symptoms in hubei, China: a descriptive, cross-sectional, multicenter study. Am. J. Gastroenterol. 115, 766-773. doi:10.14309/ajg.0000000000000620

Pasquini, Z., Montalti, R., Temperoni, C., Canovari, B., Mancini, M., Tempesta, M., et al. (2020). Effectiveness of remdesivir in patients with COVID-19 under mechanical ventilation in an Italian ICU. J. Antimicrob. Chemother. 75, 3359-3365. doi:10.1093/jac/dkaa321

Pelayo, J., Lo, K. B., Bhargav, R., Gul, F., Peterson, E., Dejoy, R., III, et al. (2020). Clinical characteristics and outcomes of community- and hospital-acquired acute kidney injury with COVID-19 in a US inner city hospital system. Cardiorenal Med. 10, 223-231. doi:10.1159/000509182

Pellaud, C., Grandmaison, G., Pham Huu Thien, H. P., Baumberger, M., Carrel, G., Ksouri, H., et al. (2020). Characteristics, comorbidities, 30-day outcome and inhospital mortality of patients hospitalised with COVID-19 in a Swiss area - a retrospective cohort study. Swiss Med. 150, w20314. doi:10.4414/smw.2020. 20314

Piva, S., Filippini, M., Turla, F., Cattaneo, S., Margola, A., De Fulviis, S., et al. (2020). Clinical presentation and initial management critically ill patients with severe acute respiratory syndrome coronavirus 2 (SARS-CoV-2) infection in Brescia, Italy. J. Crit. Care 58, 29-33. doi:10.1016/j.jcrc.2020.04.004

Potere, N., Di Nisio, M., Rizzo, G., La Vella, M., Polilli, E., Agostinone, A., et al. (2020). Low-dose subcutaneous tocilizumab to prevent disease progression in patients with moderate COVID-19 pneumonia and hyperinflammation. Int. J. Infect. Dis. 100, 421-424. doi:10.1016/j.ijid.2020.07.078

Price, C. C., Altice, F. L., Shyr, Y., Koff, A., Pischel, L., Goshua, G., et al. (2020). Tocilizumab treatment for cytokine release syndrome in hospitalized COVID19 patients: survival and clinical outcomes. Chest $158,1397-1408$. doi:10.1016/j. chest.2020.06.006

Primmaz, S., Le Terrier, C., Suh, N., Ventura, F., Boroli, F., Bendjelid, K., et al. (2020). Preparedness and reorganization of care for coronavirus disease 2019 patients in a Swiss ICU: characteristics and outcomes of 129 patients. Crit. Care Explor. 2, e0173. doi:10.1097/CCE.0000000000000173

PRISMA (2015). Transparent reporting of systematic reviews and meta-analyses. Available at: http://www.prisma-statement.org/.

Quartuccio, L., Sonaglia, A., Mcgonagle, D., Fabris, M., Peghin, M., Pecori, D., et al. (2020). Profiling COVID-19 pneumonia progressing into the cytokine storm syndrome: results from a single Italian Centre study on tocilizumab versus standard of care. J. Clin. Virol. 129, 104444. doi:10. $1016 / j . j c v .2020 .104444$
Recovery Collaborative Group (2020). Dexamethasone in hospitalized patients with covid-19-preliminary report. N. Engl. J. Med. 2020, 436. doi:10.1056/ NEJMoa2021436

Richardson, S., Hirsch, J. S., Narasimhan, M., Crawford, J. M., Mcginn, T., Davidson, K. W., et al. (2020). Presenting characteristics, comorbidities, and outcomes among 5700 patients hospitalized with COVID-19 in the New York city area. JAMA 323, 2052-2059. doi:10.1001/jama.2020.6775

Rosenberg, E. S., Dufort, E. M., Udo, T., Wilberschied, L. A., Kumar, J., Tesoriero, J., et al. (2020). Association of treatment with hydroxychloroquine or azithromycin with in-hospital mortality in patients with COVID-19 in New York state. JAMA 323, 2493-2502. doi:10.1001/jama.2020.8630

Salacup, G., Lo, K. B., Gul, F., Peterson, E., De Joy, R., Bhargav, R., et al. (2020). Characteristics and clinical outcomes of COVID-19 patients in an underservedinner city population: a single tertiary center cohort. J. Med. Virol. 93, 416-423. doi:10.1002/jmv.26252

Saleh, M., Gabriels, J., Chang, D., Kim, B. S., Mansoor, A., Mahmood, E., et al. (2020). The effect of chloroquine, hydroxychloroquine and azithromycin on the corrected QT interval in patients with SARS-CoV-2 infection. Circ. Arrhythm. Electrophysiol. 13, 8662. doi:10.1161/CIRCEP.120.008662

Sarayani, A., Cicali, B., Henriksen, C. H., and Brown, J. (2020). Safety signals for QT prolongation or Torsades de Pointes associated with azithromycin with or without chloroquine or hydroxychloroquine. Am. J. Obstet. Gynecol. 17, 483-486. doi:10.1016/j.sapharm.2020.04.016

Sentilhes, L., De Marcillac, F., Jouffrieau, C., Kuhn, P., Thuet, V., Hansmann, Y., et al. (2020). Coronavirus disease 2019 in pregnancy was associated with maternal morbidity and preterm birth. Am. J. Obstet. Gynecol. 223, 914.e1-914.e15. doi:10.1016/j.ajog.2020.06.022

Shah, S. J., Barish, P. N., Prasad, P. A., Kistler, A., Neff, N., Kamm, J., et al. (2020). Clinical features, diagnostics, and outcomes of patients presenting with acute respiratory illness: a retrospective cohort study of patients with and without COVID-19. EClinicalMedicine 27, 100518. doi:10.1016/j.eclinm.2020.100518

Sheahan, T. P., Sims, A. C., Graham, R. L., Menachery, V. D., Gralinski, L. E., Case, J. B., et al. (2017). Broad-spectrum antiviral GS-5734 inhibits both epidemic and zoonotic coronaviruses. Sci. Transl. Med. 9, eaal3653. doi:10.1126/scitranslmed. aal3653

Shekerdemian, L. S., Mahmood, N. R., Wolfe, K. K., Riggs, B. J., Ross, C. E., Mckiernan, C. A., et al. (2020). Characteristics and outcomes of children with coronavirus disease 2019 (COVID-19) infection admitted to US and Canadian pediatric intensive care units. JAMA Pediatr. 174, 868-873. doi:10.1001/ jamapediatrics.2020.1948

Shi, D., Wu, W., Wang, Q., Xu, K., Xie, J., Wu, J., et al. (2020). Clinical characteristics and factors associated with long-term viral excretion in patients with severe acute respiratory syndrome coronavirus 2 infection: a single-center 28-day study. J. Infect. Dis. 222, 910-918. doi:10.1093/infdis/jiaa388

Singh, A. K., Majumdar, S., Singh, R., and Misra, A. (2020a). Role of corticosteroid in the management of COVID-19: a systemic review and a Clinician's perspective. Diabetes Metab. Syndr. 14, 971-978. doi:10.1016/j.dsx.2020.06.054

Singh, S., Chakravarty, T., Chen, P., Akhmerov, A., Falk, J., Friedman, O., et al. (2020b). Allogeneic cardiosphere-derived cells (CAP-1002) in critically ill COVID-19 patients: compassionate-use case series. Basic Res. Cardiol. 115, 36. doi:10.1007/s00395-020-0795-1

Skipper, C. P., Pastick, K. A., Engen, N. W., Bangdiwala, A. S., Abassi, M., Lofgren, S. M., et al. (2020). Hydroxychloroquine in nonhospitalized adults with early COVID-19: a randomized trial. Ann Intern Med. 173, 623-631. doi:10.7326/ M20-4207

Spinner, C. D., Gottlieb, R. L., Criner, G. J., Arribas López, J. R., Cattelan, A. M., Soriano Viladomiu, A., et al. (2020). Effect of remdesivir vs standard care on clinical status at 11 Days in patients with moderate COVID-19: a randomized clinical trial. JAMA 324, 1048-1057. doi:10.1001/jama.2020.16349

Suleyman, G., Fadel, R. A., Malette, K. M., Hammond, C., Abdulla, H., Entz, A., et al. (2020). Clinical characteristics and morbidity associated with coronavirus disease 2019 in a series of patients in metropolitan detroit. JAMA Netw. Open 3, e2012270. doi:10.1001/jamanetworkopen.2020.12270

Tang, W., Cao, Z., Han, M., Wang, Z., Chen, J., Sun, W., et al. (2020). Hydroxychloroquine in patients with mainly mild to moderate coronavirus disease 2019: open label, randomised controlled trial. BMJ 369, m1849. doi:10. 1136/bmj.m1849 
The COVID-19 Investigation Team (2020). Clinical and virologic characteristics of the first 12 patients with coronavirus disease 2019 (COVID-19) in the United States. Nat. Med. 26, 861-868. doi:10.1038/s41591-020-0877-5

The Writing Committee for the REMAP-CAP Investigators (2020). Effect of hydrocortisone on mortality and organ support in patients with severe COVID-19: the REMAP-CAP COVID-19 corticosteroid domain randomized clinical trial. JAMA 324, 1317-1329. doi:10.1001/jama.2020.17022

Tomazini, B. M., Maia, I. S., Cavalcanti, A. B., Berwanger, O., Rosa, R. G., Veiga, V. C., et al. (2020). Effect of dexamethasone on days alive and ventilator-free in patients with moderate or severe acute respiratory distress syndrome and COVID-19: the CoDEX randomized clinical trial. JAMA 324, 1307-1316. doi:10.1001/jama.2020.17021

Toniati, P., Piva, S., Cattalini, M., Garrafa, E., Regola, F., Castelli, F., et al. (2020). Tocilizumab for the treatment of severe COVID-19 pneumonia with hyperinflammatory syndrome and acute respiratory failure: a single center study of 100 patients in Brescia, Italy. Autoimmun Rev. 19, 102568. doi:10.1016/ j.autrev.2020.102568

Vahidy, F. S., Drews, A. L., Masud, F. N., Schwartz, R. L., Askary, B. B., Boom, M. L., et al. (2020). Characteristics and outcomes of COVID-19 patients during initial peak and resurgence in the houston metropolitan area. Jama 324, 998-1000. doi:10.1001/jama.2020.15301

Von Elm, E., Altman, D. G., Egger, M., Pocock, S. J., Gøtzsche, P. C., and Vandenbroucke, J. P. (2007). The Strengthening the Reporting of Observational Studies in Epidemiology (STROBE) statement: guidelines for reporting observational studies. PLoS Med 4, e296. doi:10.1371/journal.pmed. 0040296

Wang, D., Hu, B., Hu, C., Zhu, F., Liu, X., Zhang, J., et al. (2020a). Clinical characteristics of 138 hospitalized patients with 2019 novel coronavirusinfected pneumonia in Wuhan, China. Jama 323, 1061-1069. doi:10.1001/ jama.2020.1585

Wang, D., Yin, Y., Hu, C., Liu, X., Zhang, X., Zhou, S., et al. (2020b). Clinical course and outcome of 107 patients infected with the novel coronavirus, SARS-CoV-2, discharged from two hospitals in Wuhan, China. Crit. Care 24, 188. doi:10. 1186/s13054-020-02895-6

Wang, N. (2018). How to conduct a meta-analysis of proportions in R: a comprehensive tutorial. Available at: http://rgdoi.net/10.13140/RG.2.2.27199. 00161.

Wang, X., Cao, R., Zhang, H., Liu, J., Xu, M., Hu, H., et al. (2020c). The antiinfluenza virus drug, arbidol is an efficient inhibitor of SARS-CoV-2 in vitro. Cell Discov. 6, 28. doi:10.1038/s41421-020-0169-8

Wang, Y., Zhang, D., Du, G., Du, R., Zhao, J., Jin, Y., et al. (2020d). Remdesivir in adults with severe COVID-19: a randomised, doubleblind, placebo-controlled, multicentre trial. Lancet 395, 1569-1578. doi:10.1016/S0140-6736(20)31022-9

Wang, Z., Yang, B., Li, Q., Wen, L., and Zhang, R. (2020e). Clinical features of 69 cases with coronavirus disease 2019 in wuhan, China. Clin. Infect. Dis. 71, 769-777. doi:10.1093/cid/ciaa272

WHO (2020). WHO recommends against the use of remdesivir in COVID-19 patients. Available at: https://www.who.int/news-room/feature-stories/detail/ who-recommends-against-the-use-of-remdesivir-in-covid-19-patients.

Wu, C., Chen, X., Cai, Y., Xia, J., Zhou, X., Xu, S., et al. (2020a). Risk factors associated with acute respiratory distress syndrome and death in patients with coronavirus disease 2019 pneumonia in Wuhan, China. JAMA Intern Med. 180, 934-943. doi:10.1001/jamainternmed.2020.0994

Wu, J., Huang, J., Zhu, G., Liu, Y., Xiao, H., Zhou, Q., et al. (2020b). Systemic corticosteroids and mortality in severe and critical COVID-19 patients in Wuhan, China. J. Clin. Endocrinol. Metab. 105, e4230-e4239. doi:10.1210/ clinem/dgaa627

Wu, J., Liu, J., Zhao, X., Liu, C., Wang, W., Wang, D., et al. (2020c). Clinical characteristics of imported cases of COVID-19 in Jiangsu province: a multicenter descriptive study. Clin. Infect. Dis. doi:10.1093/cid/ciaa199

Xu, K., Chen, Y., Yuan, J., Yi, P., Ding, C., Wu, W., et al. (2020a). Factors associated with prolonged viral RNA shedding in patients with COVID-19. Clin. Infect. Dis. 71, 799-806. doi:10.1093/cid/ciaa351

Xu, P., Huang, J., Fan, Z., Huang, W., Qi, M., Lin, X., et al. (2020b). Arbidol/IFNa2b therapy for patients with corona virus disease 2019: a retrospective multicenter cohort study. Microbes Infect. 22, 200-205. doi:10.1016/j.micinf. 2020.05.012

Xu, X. W., Wu, X. X., Jiang, X. G., Xu, K. J., Ying, L. J., Ma, C. L., et al. (2020c). Clinical findings in a group of patients infected with the 2019 novel coronavirus (SARS-Cov-2) outside of Wuhan, China: retrospective case series. Bmj 368, m606. doi:10.1136/bmi.m606

Yan, D., Liu, X. Y., Zhu, Y. N., Huang, L., Dan, B. T., Zhang, G. J., et al. (2020a). Factors associated with prolonged viral shedding and impact of lopinavir/ ritonavir treatment in hospitalised non-critically ill patients with SARS-CoV-2 infection. Eur. Respir. J. 56, 2000799. doi:10.1183/13993003.00799-2020

Yan, X., Han, X., Peng, D., Fan, Y., Fang, Z., Long, D., et al. (2020b). Clinical characteristics and prognosis of 218 patients with COVID-19: a retrospective study based on clinical classification. Front. Med. 7, 485. doi:10.3389/fmed. 2020.00485

Yang, X., Yu, Y., Xu, J., Shu, H., Xia, J., Liu, H., et al. (2020). Clinical course and outcomes of critically ill patients with SARS-CoV-2 pneumonia in Wuhan, China: a single-centered, retrospective, observational study. Lancet 8, 445-481. doi:10.1016/S2213-2600(20)30079-5

Yu, M., Liu, Y., Xu, D., Zhang, R., Lan, L., and Xu, H. (2020a). Prediction of the development of pulmonary fibrosis using serial thin-section CT and clinical features in patients discharged after treatment for COVID-19 pneumonia. Korean J. Radiol. 21, 746-755. doi:10.3348/kjr.2020.0215

Yu, Y., Xu, D., Fu, S., Zhang, J., Yang, X., Xu, L., et al. (2020b). Patients with COVID-19 in 19 ICUs in Wuhan, China: a cross-sectional study. Crit. Care 24, 219. doi:10.1186/s13054-020-02939-x

Zerah, L., Baudouin, É., Pépin, M., Mary, M., Krypciak, S., Bianco, C., et al. (2020). Clinical characteristics and outcomes of 821 older patients with SARS-cov-2 infection admitted to acute care geriatric wards. J. Gerontol. A Biol. Sci. Med. Sci. 2020, glaa210. doi:10.1093/gerona/glaa210

Zhang, J., Yu, M., Tong, S., Liu, L. Y., and Tang, L. V. (2020a). Predictive factors for disease progression in hospitalized patients with coronavirus disease 2019 in Wuhan, China. J Clin Virol 127, 104392. doi:10.1016/j.jcv.2020.104392

Zhang, Q., Wei, Y., Chen, M., Wan, Q., and Chen, X. (2020b). Clinical analysis of risk factors for severe COVID-19 patients with type 2 diabetes. J Diabetes Complications 34, 107666. doi:10.1016/j.jdiacomp.2020.107666

Zhang, Y., Cui, Y., Shen, M., Zhang, J., Liu, B., Dai, M., et al. (2020c). Association of diabetes mellitus with disease severity and prognosis in COVID-19: a retrospective cohort study. Diabetes Res. Clin. Pract. 165, 108227. doi:10. 1016/j.diabres.2020.108227

Zhao, X. Y., Xu, X. X., Yin, H. S., Hu, Q. M., Xiong, T., Tang, Y. Y., et al. (2020). Clinical characteristics of patients with 2019 coronavirus disease in a nonWuhan area of Hubei Province, China: a retrospective study. BMC Infect. Dis. 20, 311. doi:10.1186/s12879-020-05010-w

Zheng, S., Fan, J., Yu, F., Feng, B., Lou, B., Zou, Q., et al. (2020). Viral load dynamics and disease severity in patients infected with SARS-CoV-2 in Zhejiang province, China, January-March 2020: retrospective cohort study. BMJ 369, m1443. doi:10.1136/bmj.m1443

Zhou, F., Yu, T., Du, R., Fan, G., Liu, Y., Liu, Z., et al. (2020). Clinical course and risk factors for mortality of adult inpatients with COVID-19 in Wuhan, China: a retrospective cohort study. Lancet 395, 1054-1062. doi:10.1016/S01406736(20)30566-3

Zhu, Z., Lu, Z., Xu, T., Chen, C., Yang, G., Zha, T., et al. (2020). Arbidol monotherapy is superior to lopinavir/ritonavir in treating COVID-19. J. Infect. 81, e21-e23. doi:10.1016/j.jinf.2020.03.060

Conflict of Interest: The authors declare that the research was conducted in the absence of any commercial or financial relationships that could be construed as a potential conflict of interest.

Copyright (c) 2021 Abdelrahman, Liu, Jiang, Li, Sun, Zhang and Wang. This is an open-access article distributed under the terms of the Creative Commons Attribution License (CC BY). The use, distribution or reproduction in other forums is permitted, provided the original author(s) and the copyright owner(s) are credited and that the original publication in this journal is cited, in accordance with accepted academic practice. No use, distribution or reproduction is permitted which does not comply with these terms. 